\title{
Palma y la Perricholi
}

Por Oswaldo Holguín Callo 
Historiador. Estudió en las facultades de Derecho, y de Letras y Ciencias Humanas de la Pontificia Universidad Católica del Perú. Ha realizado investigaciones históricas y bibliográficas en Perú, España, Estados Unidos y Chile. 
Ricardo Palma (1833-1919) no conoció a Micaela Villegas, la Perricholi (1748-1819), pero oyó hablar de ella y la hizo protagonista de una tradición y personaje secundario en otras. Las siguientes glosas abordan la relación entre nuestro escritor excelso y la célebre comedianta, quien por una existencia que discurriera entre caprichos y gestos piadosos se convirtió en personaje escénico y novelesco explotado con buen éxito antes por plumas extranjeras que peruanas.

Bien señaló Raúl Porras, en magistral conferencia pronunciada en Ancón, 1947', que la Perricholi no solo es un personaje histórico sino legendario porque "como Pizarro y Santa Rosa... es uno de los pocos personajes peruanos que han trascendido del Perú al escenario universal, y es tipo auténtico de leyenda... "2, todo lo cual lo impulsó a trazar con mano maestra el cuadro de lo que sobre ella se había escrito hasta 1956. Es lástima que no llegara a publicar la biografía que su aplicado discípulo Guillermo Lohmann había anunciado con alborozo ${ }^{3}$. Después de ese año, las contribuciones historiográficas no han sido muchas pero sí esclarecedoras ${ }^{4}$, ocupando entre ellas un lugar

I Porras Barrenechea, "De Merimée a Palma. La leyenda de la Perricholi”, un estudio dedicado a la leyenda y a la historia de la comedianta expuesto en el Teatro Bahía. Porras se ocupa de la imagen de la Perricholi en las tradiciones en las pp. 46-47 de la ed. de Cultura, por la que cito (véase la bibliografía).

2 Ibíd., p. 34.

3 Lohmann Villena, El arte dramático en Lima durante el Virreinato, p. 445, n. 9.

4 V. gr. las de Bacacorzo y Aragón Noriega referidas en la bibliografía. 
destacado La Perricholi. Apuntes histórico-genealógicos de Micaela Villegas, libro de Gustavo León y León Durán 5 .

Todo hace pensar que es el Drama de los palanganas, escrito infamatorio contra el virrey Amat y sus secuaces, reveladora obra del noble limeño Francisco Antonio Ruiz Cano, Marqués de Sotoflorido ${ }^{6}$, la primera fuente impresa para conocer algo de la vida y, sobre todo, los sonados episodios que protagonizó Micaela, incorporada al séquito del rapaz gobernante y señalada por su atrevida conducta pública, motivo de escándalo y censura. Más tarde, antes y después de la Independencia, los viajeros británicos Hall y Stevenson, y los franceses Lafond y Radiguet, recogieron del pueblo limeño aquellos episodios que la memoria colectiva había retenido y seguía recordando a pesar de los cuarenta, cincuenta o sesenta años transcurridos,

5 Es una investigación que ahonda y extiende los intentos de autores tan reputados como Raúl Porras, intrigados justamente por la leyenda creada por el pueblo y los escritores sobre la Perricholi. En verdad, no se trata de simples apuntes, como reza el subtítulo, sino de un trabajo intelectual que aclara plenamente quién fue Micaela Villegas, cuál su familia y cómo su desempeño en la vida de relación, aspectos indispensables para trazar el perfil cierto y seguro de cualquier ser humano. Aunque la Perricholi es el personaje central del libro, a su lado o sirviéndole de escolta y cortejo desfilan padres, abuelos y otros ascendientes, y sobre todo sus hijos, nietos y demás sucesores hasta el día de hoy. Se aclara el tema de los dos vástagos del virrey, homónimos y contemporáneos, lo que antes de esta investigación constituía uno de los misterios de la propia existencia de la Villegas, ya de suyo numerosos y controvertidos. Micaela resulta ser no solo una criolla a carta cabal sino una mujer entroncada con familias españolas de excelente reputación, y no la "peau rouge" o "cholita" que el francés Radiguet, limeñista insigne, por otro lado, se empeñó en retratar ganado quizá por el color local de la multiétnica ciudad (Souvenirs de l'Amérique Espagnole. Chili. Pérou. Brésil, p. 135). Y como este son muchos los "asuntos perricholescos" que el sustancioso libro expone y dilucida con el debido sustento documental. Sin embargo de quedar así mejor perfilada la actriz y cantante que encandiló al público y apasionó al vicesoberano, no se podría asegurar que esté cercano el día en que la rigurosa historia arrincone a la traviesa leyenda de la Perricholi.

6 Lohmann Villena, Un tríptico del Perú virreinal: el virrey Amat, el Marqués de Soto Florido y la Perricholi. El Drama de dos palanganas y su circunstancia. 
episodios que, recreados y aderezados en sus obras, permitieron que fuera el lector europeo, especialmente inglés y francés, el primero que advirtiera los trazos de una agitada vida tejida con hilos de historia y, sobre todo, de leyenda. La comedia "La carroza del Santísimo Sacramento", notable producción de Próspero Merimée, le dio vastísima popularidad a la Perricholi, proyectando su imagen y sus gestos al nivel de los personajes de la escena universal. Más tarde, otros autores del Viejo Mundo (v. gr. Jacques Offenbach) y del Nuevo (Thornton Wilder) siguieron y han seguido explotando la liviana aunque a la postre recatada figura de la limeña que puso a sus pies nada menos que al señor de Amat y Juniet. El viajero Stevenson es muy claro al respecto: “...las personas que vayan a Lima, con frecuencia escucharán a su llegada el nombre de esta otrora bella y generosa mujer cuya hermosura ejerció tanta influencia en su admirador, el virrey..."7.

Entre nosotros, fue el intelectual, diplomático y biógrafo romántico José Antonio de Lavalle quien plasmó en 1863 el primer esbozo del trasunto vital de la Villegas, valido de algunos de los testimonios citados y de lo que aún se escuchaban sobre la cómica entre los viejos y dicharacheros vecinos de la ciudad fundada por Pizarro ${ }^{8}$. Veinte años más tarde (1883), Palma publicó su tradición "Genialidades de la 'Perricholi"”.

Palma no mencionó a la Perricholi en sus primeras tradiciones, quien al parecer solo hizo su ingreso en ellas en 1872, pero no en un papel principal sino, más bien, disminuido (en "iPues bonita soy yo, la Castellanos!”, citada más adelante). Cabe sospechar

7 Stevenson, Narración histórica y descriptiva de veinte años de residencia en Sudamérica, p. 138.

8 Lavalle y Arias de Saavedra, "La Perricholi".

9 Salió en la cuarta serie de las Tradiciones peruanas de la ed. Prince (Lima, 1883). Cito por la ed. de 1967 de Espasa-Calpe (II, pp. 351-59). 
que el tradicionista tuviera cierta resistencia para hacerla figura central de alguno de sus relatos. Y cuando finalmente se decidió a darle el lugar que merecía, la citada tradición "Genialidades...", la dedicó al ministro francés en Lima Enrique de Borges, que era su amigo y había tenido destacada participación en su salida del encierro al que fuera sometido durante algunos días por el invasor durante la ocupación de la ciudad ${ }^{10}$. Quizá pesó en su ánimo el hecho de que eran franceses los europeos que más habían escrito para revelar al mundo la existencia de la actriz criolla. Lo cierto es que no pudo reducirla a un lugar secundario, que no fue capaz de preterirla, a ella que cuando Palma nació ya tenía entre sus paisanos acrisolada fama de mujer que había hecho perder la cabeza nada menos que a un virrey severo y riguroso, quizá porque también era un amante de los placeres de la vida. No pudo pues escamotearle un lugar destacado en su vasta literatura de relatos bullentes de fantasía y realidad, humor y prosaísmo. No pudo dejar en el tintero al menos una tradición protagonizada por quien era ya un personaje ganado por la literatura y la música, un personaje sobre el cual el pueblo de Lima contaba muchos caprichos de mujer coqueta y voluntariosa, así como anécdotas que la perfilaban engreída, altiva y provocadora. Tuvo el tradicionista que tomar la péñola y trazar una tradición sobre Miquita, nombre que así trasunta cariño como sugiere una confianza rayana en la ironía. iQué raro hubiera sido que la Perricholi faltara de las tradiciones! ¡Cómo nos habría intrigado su ausencia! Sin embargo, debo decir que la Perricholi palmina no alcanza la talla de otras mujeres retratadas en las tradiciones, cosa que ya advirtió el gran historiador y profundo catador de la obra de Palma que fue Raúl Porras ${ }^{11}$.

10 Palma, Angélica. Ricardo Palma, p. 87.

11 “De Merimée a Palma”, pp. 46-47. 
"Genialidades de la 'Perricholi', vale decir singularidades de la actriz y cantante conocida por ese mote o sobrenombre, se compone de siete partes o capítulos. En el primero, Palma presenta al personaje forzando un retrato equilibrado: la Perricholi "fue una criatura ni tan poética como la retrató José Antonio de Lavalle..., ni tan prosaica como la pintara su contemporáneo el autor anónimo del Drama de los palanganas"12. Parece que nuestro escritor quiso buscar un punto equidistante, un término medio entre la pintura idealizada de su amigo Lavalle y el retrato pedestre de Sotoflorido, archienemigo de Amat. Y la verdad es que ese punto medio parece el más justo y cabal, pues se estaría muy lejos de la verdad si se suscribiera sin beneficio de inventario lo que uno y otro dijo, respectivamente, en elogio y escarnio de tan asendereado personaje de las tablas y el cotilleo.

Donde sí comete pecado mortal don Ricardo, por credulidad y, quizá, algunos puntos de soberbia, es al afirmar con convicción digna de mejor causa lo siguiente: "No es cierto que... naciera en Lima. Hija de pobres y honrados padres, su humilde cuna se meció" en Huánuco por 1739 , siendo traída a la capital por su madre a los cinco años, recibiendo escasa educación ${ }^{13}$. ¿Dónde pudo beber esa pócima, origen de tanto extravío sufrido por autores como Luis Alberto Sánchez, Ventura García Calderón y Enrique López Albújar? ${ }^{14}$ Don Ricardo no revela su fuente de información, quizá ese "imparcial y prosaico anciano que alcanzó a conocerla en sus tiempos de esplendor", quien le habría transmitido su retrato físico, materia principal de la siguiente parte:

12 Tradiciones peruanas, II, p. 351.

13 Loc. cit. Palma "se atrevió a inventar... el humilde y provinciano origen de la actriz, la supuesta fecha de su nacimiento, el supuesto físico que la adornaba y hasta el año exacto de su encuentro con el virrey Amat" (Aragón Noriega, "El teatro, los negocios y los amores: Micaela Villegas, 'La Perricholi”, p. 354).

14 Así, García Calderón afirma que "une tradition constante la faitnaitreauxenvirons de Huánuco, à Tomayquichua” (cf. León y León Durán, La Perricholi... cit., p. 8n). 
De cuerpo pequeño y algo grueso, sus movimientos eran llenos de vivacidad; su rostro oval y de un moreno pálido lucía no pocas cacarañas u hoyitos de viruelas, que ella disimulaba diestramente con los primores del tocador; sus ojos eran pequeños, negros como el chorolque y animadísimos; profusa su cabellera, y sus pies y manos, microscópicos; su nariz nada tenía de bien formada, pues era de las que los criollos llamamos natas; un lunarcito sobre el labio superior hacía irresistible su boca, que era un poco abultada, en la que ostentaba dientes menudos y con el brillo y limpieza del marfil; cuello bien contorneado, hombros incitantes y seno turgente. Con tal mezcla de perfecciones e incorrecciones podía pasar hoy mismo por bien laminada o buena moza ${ }^{15}$.

La descripción convalida lo que Palma adelanta con aire de experto catador de los atributos femeninos, vale decir que la Perricholi no fue una belleza, "pero si la gracia es la belleza, indudablemente que Miquita era digna de cautivar a todo hombre de buen gusto"16. Reconoce además que vestía con elegancia extrema y refinado estilo, y sin ser limeña "tenía toda la genial travesura y salpimentado chiste de la limeña". El retrato se completa con el necesario apunte intelectual y artístico: "Dotada de imaginación ardiente y de fácil memoria, recitaba con infantil gracejo romances caballerescos y escenas cómicas de Alarcón, Lope y Moreto; tañía con habilidad el arpa, y cantaba con donaire al compás de la guitarra las tonadillas de moda"17.Viene después lo que no podía faltar, menos en la pluma de Palma, o sea el perdido enamoramiento de Amat y el encumbramiento, a su sombra, de su juvenil querida. El hecho lo sitúa en 1762, varios años antes de su verdadera factura, cuando la Villegas

15 Tradiciones peruanas, II, p. 352.

16 Loc. cit. En “iPues bonita soy yo, la Castellanos!” (1872) había dicho que "era hembra de escasísima belleza" (Tradiciones peruanas, I, p. 51).

17 Ibíd., II, p. 351. 
era la actriz mimada y... se hallaba en el apogeo de su juventud y belleza. Era Miquita un fresco pimpollo, y el sexagenario virrey, que por sus canas se creía ya asegurado de incendios amorosos, cayó de hinojos ante las plantas de la huanuqueña, haciendo por ella durante catorce años más calaveradas que un mozalbete... ${ }^{18}$.

Palma, que calzaba algunos puntos de historiador, válese del relato para recordar lo que Amat hizo en favor de Lima y cómo, a pesar de ello, careció del favor del pueblo, que no lo quiso y exageró "sus pecadillos, llegando la maledicencia de sus contemporáneos hasta inventar que si emprendió la fábrica del Paseo de Aguas fue solo por halagar a su dama..."19. La verdad es que esa mala opinión rayana en maledicencia se sustentaba en el autoritarismo riguroso y hasta despiadado del funcionario catalán, no menos que en sus incontables latrocinios.

Apoyado en la noticia de un incidente en el teatro de Lima recogida en el Drama de dos palanganas, Palma elabora en el cuarto capítulo de su tradición toda una escena muy propia de su estilo y objetivos literarios. El Drama... refiere cómo la Perricholi dio un chicotillazo en el rostro al actor Maza, en plena función, hecho que el virrey castigó con la expulsión de la cómica y una iracunda amenaza de castigo ejemplar. Palma sazona el incidente introduciendo en el asunto a Inesilla, una actriz nueva que a la Villegas la traía "con la bilis sublevada" porque recibía ciertas preferencias del tal Masa. Lo cierto es que en la representación de una comedia de Calderón de la Barca -“iFuego de Dios en el querer bien!”- Maza, a mitad de un parlamento, murmuró en voz baja a la Villegas:

18 Ibíd., pp. 352-53.

19 Ibíd., p. 353. 
- iMás alma, mujer, más alma, eso lo declamaría mejor la Inés! Desencadenó Dios sus iras. La Villegas se olvidó de que estaba delante del público, y alzando un chicotillo que traía en la mano, cruzó con él la cara del impertinente.

Cayó el telón. El respetable público se sulfuró y armó la gran grita: 'iA la cárcel la cómica, a la cárcel!'.

El virrey, más colorado que cangrejo cocido, abandonó el palco; y para decirlo todo de un golpe, la función concluyó a capazos ${ }^{20}$.

Amat, profundamente indignado, descarga una terrible amenaza sobre su querida y rompe con ella, pero después de varios meses se produce la reconciliación de los amantes y, a poco, el retorno de Miquita al escenario, donde vuelve a recibir el caluroso aplauso del rendido público limeño,

cantando antes de la comedia una tonadilla nueva, en la que había una copla de satisfacción para el público.

Aquella noche recibió la Perricholi la ovación más espléndida de que hasta entonces dieran noticias los fastos de nuestro vetusto gallinero o coliseo.

Agrega el pícaro autor del librejo que Miquita apareció en la escena revelando timidez; pero que el virrey la comunicó aliento, diciéndola desde su palco:

- iEh! No hay que acholarse, valor y cantar bien ${ }^{21}$.

20 Ibíd., p. 354.

21 Ibíd., p. 356. El Drama... dice: “iHe [sic], no hay que turbarse, valor y hacerlo bien!” (Lohmann Villena, Un tríptico... cit., p. 195). Palma define acholarse como "intimidarse, acortarse. Este americanismo se funda en la timidez característica de nuestros indios, cuando se ven forzados a hablar con la autoridad o con personas de superior categoría" (Dos mil setecientas voces que hacen falta en el Diccionario, p. 9). El empleo de acholarse por Palma, en vez del original turbarse, podría sugerir que la Perricholi era mestiza. Si eso pensaba Palma, quizá por ello le asignó un origen provinciano y no limeño... 
Por cierto, Palma no se priva de señalar que el hecho ocasionó la frustración de la Inesilla, que no se resignó a ser una segundona en el escenario y huyó a Lurín, de donde la llevaron presa a Lima, dejando la cárcel solo después de romper su contrato... $\mathrm{Su}$ profundo conocimiento del medio teatral, de las prácticas de los actores y, en general, de todo lo concerniente al mundo de las tablas, sírvele a Palma para adobar su relato con agudas y precisas explicaciones que enriquecen mucho la historia y le dan un aire de verdad que convence al lector. No menos sabrosas son sus alusiones a la actualidad política.

En los capítulos 5, 6 y 7, Palma da cuenta, respectivamente, de las coplas que circularon en Lima al dejar Amat el cargo de virrey; del archifamoso episodio de donación por la Perricholi de su carroza a la Iglesia para llevar la extremaunción a los moribundos; y del retiro de aquella de las tablas cuando su poderoso amante partió a España, iniciando entonces una existencia honorable y bienhechora, vistiendo el hábito de las carmelitas y socorriendo a los desventurados, en frase de Radiguet que cita a manera de colofón. Con afán de anticuario que debemos agradecer pues el original se hizo cenizas en 1943, Palma reproduce el texto del romancillo titulado "Lamentos y suspiros de la Perricholi por la ausencia de su amante el señor don Manuel de Amat a los reinos de España", manuscrito de la Biblioteca Nacional no carente de arte que trata con respeto a la célebre cómica. Además, como ratificando su competencia en el tema, se permite corregir la oportunidad de la exhibición de la Perricholi en carroza - no los festejos por haber recibido cierta condecoración el virrey sino la fiesta franciscana de la Porciúncula ${ }^{22}$ - y da cuenta de haber contemplado en el patio de una casa-huerta de la Alameda, señalada como curiosidad histórica, "el carruaje de la Perricholi, que era de forma tosca y

22 Lavalle aceptó la corrección ("La Perricholi”, p. 419n). 
pesada, y que las inclemencias del tiempo habían convertido en mueble inútil para el servicio de la parroquia"23. Puedo confirmar el aserto palmino pues, en efecto, El Comercio informó en 1859 que en un depósito de vejeces situado por el Patrocinio, vale decir en o cerca de la Alameda, se hallaba la carroza de marras, que describió acompañada de la crónica de la tradición oral que le otorgaba a esa vetustez un aire de vitalidad y picardía ${ }^{24}$. ¿Fue ese el carruaje en el que Miquita lució su figura y vanidad ante la sociedad que así admiraba como condenaba su audacia? No hay forma de saberlo, pero qué mucho si no lo hubiera sido, el pueblo así lo creía y la versión vino a enriquecer esta poliédrica leyenda limeña.

Debo señalar que no es "Genialidades..." la única tradición referida a la Villegas pues en "Rudamente, pulidamente, mañosamente" (1873) ya Palma la había sindicado por su derroche y "lujo insultante" 25 y en "El príncipe del Líbano" (1878) había ponderado su afición a las joyas ${ }^{26}$. En efecto, el tal príncipe era un turco impostor que explotaba en Lima la credulidad de la gente y había prometido hacerlas princesas a dos jóvenes, una de las cuales sospechó de él y forzó la confesión escrita del griego que le servía de criado y cómplice. Fue entonces que Miquita Villegas recibió de una tapada la citada confesión; esa noche, cuando Amat fue a su casa a cenar, se dio este diálogo:

- ¿Y qué hay de nuevo, Manuel?

- Nada, hija mía. Te repetiré lo que dice el refrán limeño:

El ojo del Puente, el Baratillo y el pan, como se estaban están $n^{27}$.

23 Tradiciones peruanas, II, p. 359.

24 El Comercio, Lima, 14 nov. 1859, p. 2, cols. 2-3, crónica de la capital.

25 Tradiciones peruanas, I, p. 305.

26 Ibíd., III, pp. 140-41.

27 Ibíd., III, p. 140. Variante: La pila, el puente y el pan, como se estaban se están ("Las cuatro pppp de Lima”, 1887, ibíd., IV, p. 106). 
Entonces, la Perricholi le dice que sin tener obligación "sé más que su virrey..., y cosa grave..., gravísima, plus quam gravissima!”, latinajo que pronuncia con superlativo énfasis para ponderar la importancia de su secreto, lo que le facilita sacarle a su poderoso amante la promesa de obsequiarle, por su próximo cumpleaños, "unas arracadas de brillantes con perlas de Panamá, tamañas como garbanzos". Amat le pregunta:

- ¿Qué tiene que ver tu santo con la noticia?

- Mucho, señor mío, porque yo no doy noticias gordas sin promesa de alboroque. Toma y lee ${ }^{28}$.

Haya consultado o no fuente que sostenga la versión, el hecho es que Palma carga las tintas para resaltar la codicia de la Villegas y las artes femeniles que empleaba para alcanzar sus propósitos materiales.

En “iPues bonita soy yo, la Castellanos!" (1872), Palma refiere las ansias de opacar a la Perricholi de Mariquita Castellanos, joven morenita limeña de belleza singular que, como aquella, gozaba de los favores de un viejo conde que la había hecho su amiga. En efecto, al darse el memorable episodio del paseo público y la donación de la carroza, la Castellanos juró superar a su émula y lo logró en la fiesta del Rosario, presentándose humildemente vestida pero llevando en brazos de una criada un perro faldero adornado con un collarín de oro macizo "con brillantes como garbanzos" 29 , mascota y joya que en el acto donó a un hospital carente de rentas. El gesto le valió ganarse la simpatía del pueblo y de la aristocracia, lo que habría perdido la orgullosa Perricholi.

28 Ibíd., III, p. 140.

29 Ibíd., I, p. 53. 
Hay en el tema de Palma y la Perricholi un hecho paradójico que el tradicionista limeño ignoró del todo y nosotros sabemos gracias a León y León. No supo don Ricardo que la actriz vino al mundo en una vivienda frontera de aquella que en la calle del Puno, a escasos metros de la Inquisición y de la Universidad, se señala como escenario de su propio nacimiento allá por 1833 . Si lo hubiera sabido, quizá nos habría regalado frutos más sazonados de su pícara péñola, como aquellos que solía ofrecer cuando describía los ojos, la boca y el palmito de las hijas de Eva nacidas a la vera del río hablador. No lo hizo y quizá hasta padeció esa "prevención inconsciente" que Raúl Porras cree advertir en el trato que dio a la inolvidable comedianta ${ }^{30}$. Pero ello no impide constatar que fue él el primer peruano que hizo de la Perricholi no solo un personaje histórico, aunque menos etéreo y gentil que el de su compañero de academia José Antonio de Lavalle, sino literario ${ }^{31}$. Sin duda, Palma contribuyó a su popularidad en el ámbito hispanohablante, pues obras en francés como las del marino Radiguet o del literato Merimée, o en inglés como las de los viajeros Hall y Stevenson, no estaban al alcance del vasto público en lengua de Castilla. La difusión de las tradiciones hizo posible que la Perricholi dejara de ser un personaje abordado solo por autores europeos. Es más, Palma le concedió a la Perricholi el aire limeño y criollo que aquellos no podían darle. Y, lejos de sus habituales preferencias, evitó expresamente asignarle definidas notas raciales, señal quizá de que intuía el resbaloso campo en el que podía caer.

Sin embargo, hay aún otra paradoja en este peliagudo asunto. Ella consiste en que Palma, a pesar de proponerse desmitificar y humanizar la figura de la actriz, a pesar del tono aclaratorio

30 Acaso por ello, afirma, fue el patrocinador de la leyenda sobre su origen huanuqueño ("De Merimée a Palma..." cit., p. 46).

31 “...fue Palma quien dio verdadera forma a la leyenda” (Aragón Noriega, "El teatro, los negocios y los amores..." cit., p. 356n). 
y apodíctico con que redacta sus "genialidades", introdujo sin sospecharlo un nuevo matiz en la leyenda, que fue asegurar con paladina convicción que aquella había nacido no en Lima sino en Huánuco, lo que más tarde daría pie a que el parto se situara en el idílico pueblo de Tomayquichua, en las cercanías de esa ciudad del lado oriental de la cordillera ${ }^{32}$.Así, sin proponérselo, don Ricardo siguió los pasos del pueblo de Lima, creador anónimo aunque principal de unos relatos, anécdotas y episodios que configuran la deleitosa trayectoria de una de sus vecinas más representativas. Por cierto, creo que debemos agradecerle tan tremendo desliz, pues su delirante equívoco es causa y razón de que se perpetúe la leyenda en un paraje de nuestra serranía, en un rincón antes desconocido por el mundo y hoy visitado por propios y extraños. Suerte de rey Midas literario, el mago de las tradiciones que fue Palma toca el pasado con su varita mágica, vulgo pluma, pronuncia un conjuro y convierte a una limeña limeñísima en hija de nuestros Andes, tal como a nosotros nos transforma en embelesados lectores cada vez que abrimos su libro inigualable.

\section{Bibliografía.}

Aragón Noriega, Ilana Lucía. "El teatro, los negocios y los amores: Micaela Villegas, 'La Perricholi’", en Pardo-Figueroa Thays, Carlos; y Dager Alva, Joseph (dirs.). El Virrey Amat y su tiempo (Lima, Pontificia Universidad Católica del Perú, Instituto Riva-Agüero, 2004), pp. 353-433.

Bacacorzo, Gustavo. La Perricholi. Da. Micaela Villegas, nulidad y reposición históricas. Lima, G. Herrera, 1994.

32 Ventura García Calderón lo afirmó en 1940 y Enrique López Albújar en 1943 (León y León Durán, La Perricholi... cit., pp. 8 y 9). 
Lavalle y Arias de Saavedra, José Antonio de. "La Perricholi", en La Revista de Lima (Lima, 15 mar. 1863), 7: 84, pp. 221-30; y en sus Estudios históricos (Lima, Lib. e Imp. Gil S. A., 1935), pp. 413-21.

León y León Durán, Gustavo. La Perricholi. Apuntes históricogenealógicos de Micaela Villegas. Lima, Designgroup, 2011. 2a ed. corregida y aumentada.

Lohmann Villena, Guillermo. El arte dramático en Lima durante el Virreinato. Madrid, Escuela de Estudios Hispano-Americanos de la Universidad de Sevilla, 1945.

----- (ed.). (Ruiz Cano y Sáenz Galiano, Marqués de Soto Florido, Francisco Antonio). Un tríptico del Perú virreinal: el virrey Amat, el Marqués de Soto Florido y la Perricholi. El Drama de dos palanganas y su circunstancia. Estudio preliminar, reedición y notas por... Chapel Hill, University of North Carolina, Department of Romance Languages, 1976.

Palma, Angélica. Ricardo Palma. Buenos Aires, Ediciones Argentinas "Cóndor", 1933.

Palma, Ricardo. Dos mil setecientas voces que hacen falta en el Diccionario. Papeletas lexicográficas. Lima, Imp. La Industria, 1903.

Tradiciones peruanas. Madrid, Espasa-Calpe, 1966-1967. 6 vols.

Porras Barrenechea, Raúl. "De Merimée a Palma. La leyenda de la Perricholi”, en La Prensa, Lima, 26 ene. 1947, p. 5, retrato; y, solo como "De Merimée a Palma", en Cultura, Lima, ene.mar. 1956, 1: 1, pp. 34-57.

Radiguet, Max. Souvenirs de l'Amérique Espagnole. Chili. Pérou. Brésil. París, Michel Lévy Frères, 1856. 
Ruiz Cano y Sáenz Galiano, Marqués de Soto Florido, Francisco Antonio. Ver Lohmann Villena, Guillermo.

Stevenson, William Bennet. Narración histórica y descriptiva de veinte años de residencia en Sudamérica. Quito, Ediciones AbyaYala, 1994. 